\title{
Retos y tensiones de la Formación Docente en el actual proceso de transformaciones
}

Marta Ofelia Chaile

Universidad Nacional de Salta

\section{Resumo}

El artículo expone los resultados de un estudio teórico sobre el tema Formación Docente (FD) en relación con el juego de lo social. Se efectúa un análisis general de las condiciones estructurales que, a nivel de globalización, inciden en la configuración política regionallocal. Luego, asumiendo el enfoque de la regulación, se interpreta cómo las decisiones de la política educacional promocionan o estabilizan las funciones, perfil y actuación que el docente desempeña. La reflexión sobre el tema es objeto de estudio en proyectos de investigación que se llevan a cabo en Salta, Argentina. La metodología de abordaje incluye un rastreo histórico evolutivo desde los '60-'70 a la actualidad, argumentando y comparando fuentes conceptuales e interpretativas que - en la región - fundamentan la función asignada al maestro y al profesor. Se complementa el análisis epocal considerando factores sociales, históricos, culturales que lentamente se asumen en el cambio del perfil profesional docente. Esta suerte de inmutabilidad formativa docente resultaría coherente con la política de regulación que impone el gobierno.

Sin embargo, la potencia del movimiento social que origina la globalización en los últimos tiempos, conduce a cambios profundos en la preparación de los docentes, bajo la modalidad de reformas y transformaciones. Pese al interés del gobierno por modificar la formación docente, continúa efectuándose un manejo político coactivo e interesado, que repercute en los órdenes de la gestión y la práctica institucional de la formación.

Finalmente se postulan principios a considerar para asumir el reto de las transformaciones en la formación docente local.

\section{Palavras-chave}

Formación Docente - Política educativa regional - Enfoque de regulación de la formación docente.

Correspondência:

Marta Ofelia Chaile

Consejo de Investigaciones de la

Universidad Nacional de Salta

Av. Bolivia, 1550, Box 6 Área Física

Salta (4400) - Argentina

e-mail: chailem@unsa.edu.ar 


\title{
Challenges and tensions of initial teacher education in the current process of transformations
}

\author{
Marta Ofelia Chaile \\ Universidad Nacional de Salta
}

\begin{abstract}
The article describes the results of a theoretical study on the issue of Teacher Education and its social interplay. It develops a broad analysis of the structural conditions which, at the globalization level, impinge upon the regional-local political configuration. Adopting the viewpoint of the regulations, the text then interprets how the decisions of educational policies promote or stabilize the functions, profiles and actions performed by the teacher.

The reflection about this issue is the object of study of research projects carried out in Salta, Argentina. The methodology employed includes a survey of the historical evolution since the 1960s and 1970s up to this day, arguing and comparing conceptual and interpretive sources which - in that region - give support to the function assigned to the teacher. The period analysis is supplemented by the consideration of social, historical, and cultural factors that are gradually incorporated along the changes in the profile of the professional teacher. This kind of immutability of teacher education would be consistent with the regulation policy imposed by the government.

However, the power of the social movement resulting from the recent globalization process has triggered profound changes in teacher education in the shape of reforms and transformations. Despite the government's interest in modifying teacher education, it continues to practice a politically-oriented policy with repercussions to the spheres of institutional management and practice of teacher education.

Finally, principles are put forward for consideration with a view to face the challenges of the transformations of local teacher education.
\end{abstract}

\section{Keywords}

Teacher education - Regional education policy - Viewpoint of regulation of the teacher education.

\footnotetext{
Contact:

Marta Ofelia Chaile

Consejo de Investigaciones de la

Universidad Nacional de Salta

Av. Bolivia, 1550, Box 6 Área Física

Salta (4400) República Argentina

e-mail: chailem@unsa.edu.ar
} 


\section{Un panorama de cambios que conduce a cambios en la función docente}

En las sociedades del hemisferio sur la función que cumple la escuela y particularmente la actuación profesional docente se han visto progresivamente modificadas - y con aceleración en los últimos tiempos - por efecto de factores de índole social, por cambios en las concepciones políticas, por la emergencia de nuevos requerimientos profesionales ante la sociedad que se modifica, por la intensificación de la comunicación vía internet, todo lo cual conduce a un replanteo de la organización y las metas educacionales que se persiguen.

Las políticas educacionales procuran actualizar la estructura del sistema educacional, poner al día la currícula y - particularmente capacitar a los docentes - sea desde la Formación Inicial o a través de la actualización profesional para que incorporen competencias, habilidades cognitivas y estrategias didácticas de mejor encaje con las condiciones de trabajo. En especial ésta ha sido la atención prestada por el movimiento de reforma que se inicia en el país durante la década de '90 y que, con variantes, hoy continúa.

La propuesta del docente innovador, reflexivo, comprometido, se ha dejado escuchar en los variados escenarios de actualización y capacitación. Sin embargo - aunque hay logros alcanzados tras estos principios - la realidad docente muestra niveles de disconformidad, conflicto y desazón, que bien conviene revisar en sus causas y presupuestos, para adecuar el proyecto de trabajo en torno al alcance de un profesional que satisfaga los requerimientos formativos que la región requiere.

Se propone un análisis de las condiciones locales en lo social, en lo político y particularmente - su incidencia en las funciones que el docente desempeña, considerando el contexto general de los hechos y sucesos. La reflexión sobre el tema es objeto de estudio en proyectos de investigación que rastrean desde las fuentes conceptuales e interpretativas que en la región dan origen a la función asignada al maestro y al profesor; se avanza luego a considerar el inter-juego de factores sociales, históricos, culturales y su grado de incidencia en el lento cambio del perfil profesional docente. Se estima que un notorio movimiento social como el que origina la globalización en los últimos tiempos, conduce a cambios profundos en la preparación de los docentes. Sin embargo, la derivación o aplicación de los principios de cambio en regiones del sur americano revisten la particular influencia de modos sociales genuinos, que afectan los procesos de formación y actuación docente, así como las funciones de la escuela en el medio.

\section{Alcance de cambios desde los 70}

Aproximadamente desde la década de '70 (séc. XX) en adelante la sociedad observa y experimenta notables modificaciones en los órdenes laboral, cultural, social, político, económico, de tal modo que llega a estructurarse un panorama marcadamente diferenciado tanto por sus alcances como por sus consecuencias, no siempre benéficas.

En relación con el desarrollo del capitalismo internacional - que se intensifica en la época - al pais ${ }^{1}$ le corresponde la continuidad de su rol de subsidiario de materias primas y algún grado de industrialización, ya no sólo de tipo sustitutivo sino basado en la posesión de los minerales, hidrocarburos y en la técnica mecánica.

Se considera que hasta esta época se desenvuelve el denominado Estado de Bienestar y que a partir de allí ingresa en una franca desintegración, produciendo notables colapsos. Durante su vigencia (aproximadamente después de la Segunda Guerra Mundial al '75) se difunde entre la población un nivel más o menos parejo de acceso a las fuentes laborales muchas de ellas del mismo orden estatal - a la salud, a la vivienda, a la educación.

\section{Referencia a la República Argentina.}


Particularmente en educación la política acentúa la expansión de la escolaridad, formaliza niveles, organiza direcciones para esos nuevos niveles y moderniza el currículum

En este período ('60-'70) se difunde el movimiento llamado "tecnicismo", acompañando al desarrollismo socioeconómico. Basado en la importancia de los principios del desarrollo industrial, se traspasa al orden educativo y al ámbito de la organización escolar y la didáctica, un enfoque y una práctica fundamentados en el planeamiento, la previsión, la racionalidad que aseguren logros anticipados y un proceso eficiente. Se procura la superación de conductas tradicionalmente basadas en la repetición, el costumbrismo, el ritualismo.

Las directivas respecto a la adopción del nuevo enfoque por los organismos educacionales, su cuerpo técnico y de supervisión, así como los directivos de escuelas, marcan diferencias respecto a anteriores periodos. El movimiento se refleja en orientaciones resolutivas, en acciones de capacitación docente, en tanto que lo más notable en la Formación Docente (FD) incluye el proceso de “terciarización” de los estudios o el pase del Normalismo al nivel superior no universitario de enseñanza. Este conjunto de modificaciones señalan la emergencia de la modernización en el país, que se arrastra hacia su interior, donde se asume lentamente.

Dada la rivalidad política instalada entre Estados Unidos y el bloque comunista, la región sureña de América opera sólo como subsidiaria y eventual partidaria, dentro de las filas del liberalismo. En los países centrales europeos se desarrollan movimientos anti-política, anti-universidad tradicional y se propagan líneas vanguardistas del arte, la música, el baile, nunca antes vistos, que tienen su resplandor y reflejo en el orden local.

En lo social se alcanza a mejorar los niveles de producción en el país, generando un estado de bienestar que se esparce para un buen número de la población. Los partidos políticos, en especial el radicalismo, buscan concretar un programa de acción que lo aleje del populismo peronista (derrocado en el '55) pero no se alcanza la necesaria estabilidad. La época incluye la insurgencia militar del Onganiato $^{2}$ y posteriormente de los militares de las tres armas (encabezado por Videla), que altera el estado de democracia y genera posiciones de retroceso para el país, tanto en lo civil como en lo económico y cultural.

La política educacional sufre una notable alteración durante el gobierno militar, instalándose una fuerte persecución a la población docente y estudiantil militante. Se declara la intervención de las universidades y se procede a cambiar el currículum de enseñanza, se clausuran los centros estudiantiles y se inicia la expulsión de maestros, profesores indicados como "subversivos" al orden militar y sus principios.

El interior del país, en particular el noroeste, en este período vivencia los cambios desde un bajo nivel de acceso a la modernidad, a la expansión de programas de viviendas, a algunas obras públicas, a cierta expansión de la escolaridad, pero sin desaparecer la interpretación fortuita de los sucesos sociales, hay una lenta instalación del pensamiento racional alrededor de la planificación de las acciones, no se promociona la autenticidad de la participación política y la educación se expande pero no "ilumina", en el sentido develador que propicia la opinión crítica. La Universidad pública se halla limitada en su accionar y concentrada alrededor de sus intereses.

La FD no experimenta grandes cambios en la práctica, salvo las insinuaciones de modificación programadas y ejecutadas con base en el "tecnicismo".

Los '80 en el país están marcados por signos poco propicios. En primer lugar continúa instalado el gobierno militar, que hacia el '82 inicia el proceso de convocatoria a elecciones libres, lo que se concreta en 1983. En segundo lugar los acontecimientos externos de avance

2. Onganiato: insurrección militar de 1966 encabezada por el Gral. Juan C. Onganía. 
capitalista neoliberal y libre importación acarrean una política económica negativa lo que, unido a la privación de libertad durante el militarismo y a la pérdida del poder adquisitivo luego, hacen que la llamada "década perdida" ${ }^{3}$ indique el estado en que la Argentina inicia la generalización de la pobreza, la pérdida de fuentes de trabajo, el bajo PBI, la escasa recaudación, la mala calidad educativa y una franca caída de representatividad en el orden internacional. Problemas de política interna y la incidencia del capitalismo neoliberal hacen crisis en el gobierno, precipitando la entrega del mando del país por el Dr. Alfonsín al Presidente C. Menem ('89).

Luego del retroceso ideológico-curricular sufrido por la FD durante el militarismo, la reinstalación de la democracia impone su revisión, la que se concreta a partir de 1984, así como el proceso de capacitación y perfeccionamiento docente. La tarea es importante, pero la modificación es lenta y - en general las bases de fundamento del cambio se asignan a los ideales democráticos antes que una interpretación paradigmática estructural.

La función docente asignada por el militarismo, limitada y a-crítica, reproductivista y no científica, perdura en el tiempo y es auxiliada por otros factores que perturban el trazado de las nuevas políticas educacionales. El bajo salario, las condiciones de trabajo inestable, las dificultades de promoción en la carrera docente, generan condiciones de malestar que se solucionan parcialmente durante la democracia.

Es que la escuela, centro de la vida comuntaria, en especial en el interior, obra como núcleo donde se expanden los avatares de la vida ciudadana. Es allí donde la conducta del escolar refleja el tipo de hogar y las condiciones de vida en que se desenvuelve; es la escuela la que asume la tarea sustituta reasumiendo el rechazado principio normalista - y de nuevo el docente rearma sus estrategias, que - más allá de cualquier paradigma explicativo - permite enfrentar difíciles situaciones para las que no hay "formación", sino "experiencia".

\section{Los cambios de la sociedad globalizada y su influencia}

Se reconoce que la emergencia de lo que se ha dado en llamar Sociedad de la Información (Castells, 1995; Becerra, 2003a) caracterizada por la irrupción de las Tecnologías de la Información y Comunicación (TIC) - acrecienta y modifica los procesos de almacenamiento, procesamiento y transmisión de información, incidiendo a su vez en los modos de producción, la organización laboral y el perfil de competencias requeridos en el área del empleo.

Estos cambios no se dan de forma aislada sino se ven favorecidos por las políticas de desregulación, liberalización y privatización de las economías (Pedró; Roló, 1996), que a su vez se conjugan con argumentos que limitan y echan críticas sobre el Estado de Bienestar. De modo que tanto la cobertura social como los distintos grados de proteccionismo brindados por aquél han ido finalizando abruptamente (cut up) acusando que su funcionamiento se degradó burocráticamente y se tornó ineficaz e ineficiente.

Los procesos globalizadores (Chomsky; Dieterich, 1996), por su parte, descansan en la notoria expansión capitalista a partir de una nueva lógica de crecimiento y acumulación que se funda en la emergencia de la microinformática y el consecuente modo de desarrollo informacional. Sobre la base de sus alcances y modus operandi se manipulan inversiones, transferencias, ventas y ofertas, apertura de nuevos mercados, fusiones de empresas e intereses, que a su vez requieren nuevos procesos de gestión y marketing (Brunet; Valero, 1998).

Sin embargo, y aún cuando se ha difundido una interpretación benéfica de la Globalización, en la medida en que "acerca pueblos y naciones”, hay una clave intrínseca del proceso capitalista que se reedita con mayor alcance a raíz del fuerte impacto de venta y reditúo, y es que multiplica el consumo pero retiene las

3. Década perdida: período de la historia argentina entre 1980-90, de profunda crisis y deterioro. 
ganancias. En realidad se aumenta la brecha de la desigualdad social entre países y en su interior.

La Globalización, difundida sobre la base de principios ideológicos que infunden esperanza y credibilidad, tales como el progreso/adelanto, el desarrollo/crecimiento, la integración/acercamiento genera fantasía e interés, propiciados por afanes propagandísticos y el mercadeo en esencia. Los usuarios, los clientes, el nuevo ciudadano, si bien acceden de modo más directo a las fuentes del conocimiento - auxiliado por la conexión microinformática o teleinformática - lo hacen en gran medida para aprovechar la oferta-venta de productos generados a "su nivel y calidad".

En toda esta etapa el valor asignado al conocimiento es fundamental, confiándose en él el origen del desarrollo de especies, procesos, estrategias, anticipaciones, organización, etc., de planes de acción en los variados órdenes de la acción humana. Pareciera que el conocimiento "supera" a la naturaleza, por lo que el hombre siente que, poseyéndolo, concentra el poder. Esta nueva forma de enriquecimiento origina las consecuentes polémicas, críticas y disputas a su alrededor.

Los finales del siglo XX e inicios del XXI presentan un mapa político que ha modificado (Chomsky, 1999) el estatismo de Europa, enfrentado a su potencia rival, EE UU. Nuevos pueblos - y con ellos su etnia, lengua, cultura - reaparecen con variados grados de desarrollo, lo que a su vez alienta o justifica otros medios colectivos de buscar el bienestar, tales como la Unión, la Comunidad. Los restantes continentes, Africa por ejemplo, han sufrido desplazamientos de grupos poblacionales que llegan a reestructurar la geografía, sobre la base del reconocimiento de causas culturales, raciales, políticas y aún de subsistencia. América Latina, durante este período, ha variado pero sobre todo por la vivencia de procesos políticos que la hicieron transitar desde los regímenes autoritarios a las democracias particularizadas de sus estados y gobiernos. Los países, las comunidades también intentan la concurrencia colectiva en bloques de acción y protección (Mercosur, Alca) acercándose y alejándose de los grandes países, en distintos grados de desarrollo de los procesos.

En estos treinta años de marcadas transformaciones, la sociedad y sus modos de sentir, de expresarse, de convivir, de relacionarse, también varían. A ello contribuyó la emergencia a su vez resultado de la confluencia de hechos y factores justificantes - de manifestaciones artísticas que fueron internacionalizando su producción, reflejando sentimientos y opiniones hasta entonces vedados; la apertura comunicacional y los desplazamientos asegurados por la transformación de las vías de contacto y transporte, el revisado posicionamiento de la mujer como protagonista de papeles en el orden laboral (más tarde en otros ámbitos), los cambios en la interpretación de esquemas del poder, sexo, clases y etnias, la emergencia del arte en tanto expresión humana, creativa, discutible, contra-hegemónica a la naturalizada forma social del quehacer posterior a la Segunda Guerra.

\section{Un mundo de cambios frente a los procesos de Formación Docente}

Los últimos cambios, por su potencia e importancia, conducen a la necesaria revisión del proyecto educacional, de la orientación del movimiento escolar, del sentido de las instituciones. Los sistemas educacionales comenzaron a experimentar - de a poco inicialmente pero en los últimos tiempos con notoriedad - el desajuste, la des-actualización, el alejamiento de sus bases fundacionales, normativa y objetivos de permanencia (Brunet; Valero, 1997); de allí la necesidad de su reformulación.

Es que la emergencia del nuevo modelo comunicacional e informacional, precedido por el otrora auge de los medios audiovisuales, satisface, interesa y entretiene al público - incluyendo al escolar -, torna monótonas las clases de las aulas, compite con la predominancia de la figura docente, conduce a rechazar la estructura curricular en espacios y tiempos reglados a la antigua. 
En los países centrales, variados Informes, ya desde los '80, (Carnegie Fondation, 1986; Holmes Group, 1986) dan cuenta del desajuste curricular del sistema y de la función docente, por lo que las autoridades deciden abordar un proceso de planificación estratégica en torno a objetivos y cambios inmediatos.

1 - Por un lado, proceden a incorporar nuevas funciones y competencias a lograr en los sujetos de la educación, conforme lo requiere el mundo de la producción y el empleo

2 - Para ello abordan con intención el planteo de frecuentes relaciones a mantener con el área laboral, organizando dispositivos de contacto, monitoreo de proyectos, evaluación de acciones

3 - Inician un proceso de cambio respecto a la FD, concientes de la necesidad de conformar un profesional apto, competente para la preparación de las jóvenes generaciones que cualificarán para actuar en el siglo XXl.

Los resultados de la adopción de este paquete de medidas e imposición técnica se hallan en constante reajuste, siendo intención de la política de los paises centrales seguir resguardando la figura y actuación docente. Otros planteos postulan la superación de su rol o al menos se busca disminuir la confianza concedida, mientras se perfeccionan variados medios y estrategias, o se ajustan para su reemplazo (Braslavsky, 2000).

\section{Transformaciones en el orden local: su particularidad}

El estado de las sociedades latinoamericanas frente al panorama de profundas transformaciones signadas por la Globalización muestra su vulnerabilidad, agregada a las condiciones de privación, limitación y riesgo que las caracterizan. Por razones de más fundamentado reconocimiento, en este apartado se hará referencia al particular caso argentino.

Desde finales de los '80 y particularmente en los '90 se precipita en el país una políti- ca de adhesión a los principios del neoliberalismo, desencadenando - como consecuencia - la desnacionalización de organismos y organizaciones estatales que solían acoger laboralmente a un significativo número de la Población Económicamente Activa.

Un nuevo marco interpretativo se asume en el período. Se divulgan ideas descalificatorias respecto a la burocracia estatal, su in-efectividad y la necesidad de reemplazar al Estado por la gestión privada, la que demuestra una preocupación interesada por regentear áreas sociales como el manejo y distribución del agua, los hidrocarburos, las telecomunicaciones, los ferrocarriles y el transporte en general. Tanto los sectores del ejecutivo como el mando legislativo - excepto alguna oposición, muestran conformidad para aprobar la política de cambio, que - en realidad - actúa como un fideicomiso de intereses extranjeros, bajo la forma de consorcio internacional.

Dada esa confirmación en el país, a la denominada "década perdida", le sigue un oscuro periodo en que se ve desaparecer el sistema de beneficios y prestaciones sociales legislados durante la vigencia del Estado Proveedor, arrasando con el derecho laboral, el regimen jubilatorio tipo sistema de reparto, el acceso al consumo. A cambio, se difunde la nueva condición social de la pobreza extendida, la inequidad social y la vulnerabilidad cívica.

En el orden de las comunicaciones y la información, se imponen modelos generados por la divulgación de las TICs, el entretenimiento televisivo, la popularización de los reality show, en una mezcla de actualización técnica de la población y de liviandad festivas. Se privatiza y concentra la emisión de noticias (García Canclini, 1999) a través de consorcios que expanden y delimitan el corte informativo en el mundo.

En lo ideológico, se mantiene la rivalidad partidario-política, aunque también se difunde el descreimiento en las promesas electorales. Se constatan el abandono de las plataformas programáticas, el aprovechamiento personal de la participación política, el nepotismo en las 
acciones del gobierno. Sin embargo, como en una constante cíclica, cada nueva etapa del gobierno acarrea más adhesiones que rechazos, quizás explicable desde la irreflexión de las conductas, la internalización de la sumisión o el juego de la última esperanza.

Regiones tradicionalmente estancadas como el noroeste ven profundizar sus condiciones de vida, ahondar la línea de pobreza, emerger los "nuevos pobres", por efectos de la pérdida del trabajo estatal, característico de la inserción formalizada de la población. La desaparición de las empresas estatales deja a poblaciones enteras desoladas por la falta de ocupación, de horizontes de vida y de concentración familiar alrededor de la actividad laboral (ferrocarriles, YPF...).

Todo confluye para destruir el tejido social en forma de desocupación, desaliento, vagabundeo, intensificación de problemáticas de violencia, robo, drogadicción y el deterioro de la salud de la población. La región también se caracteriza por el aumento demográfico, lo que ahonda las condiciones de pobreza.

\section{Reformas en el sistema educacional}

En este período el sistema educacional ha sido objeto de reformas siguiendo los lineamientos de la transformación educativa que impone el Ministerio de Educación de la Nación. Se trata de modificaciones que se vinieron asumiendo desde tiempo atrás, en que progresivamente la escuela y el sistema fueron demostrando incompetencia y descrédito (Braslavsky, 1999), pero que hacia los '90 se impone en consonancia con los movimientos de transformación derivados de la aplicación de un modelo neoliberal. La reforma sigue, básicamente la estrategia de la descentralización, pero además le interesa promover la autonomía institucional y profesional, al tiempo que se interesa por la dotación de condiciones que favorezcan el aprendizaje. Reserva para el Estado la función de evaluación y control.

La puesta en práctica del modelo de la reforma choca en la realidad con las tradiciones derivadas de un modelo educacional decidido a nivel ministerial, más otras situaciones poco propicias en el medio. Se alude al estilo de las políticas clientelísticas y de baja credibilidad que imperan en la región, que tergiversan los objetivos declarados, las modalidades de acción y la inversión prometida. Se alude también al estilo dependentista en que directivos y docentes han sido formados durante la vigencia del regimen anterior, por lo que solicitar autonomía, innovación y profesionalidad requiere todo un esfuerzo de reorganización institucional y de autocrítica docente. Si a ello se agrega el problema de la semiprofesionalidad docente, su baja salarial, la escasa motivación ante el estancamiento de la carrera, se explican algunas de las dificultades para alcanzar las metas planteadas por la reforma.

En el amplio escenario de incidencia de la pobreza, el desempleo y el retiro del Estado, las políticas que se implementan se tornan insuficientes e ineficaces. El acondicionamiento infraestructural de los edificios escolares, no resulta suficiente para albergar la densidad de poblacional infantil perteneciente a familias desplazadas desde sus sitios de origen al área periférica de ciudades de la región, ante el cierre, disminución o modificación de sus fuentes laborales. Los programas compensatorios adoptados por la reforma, efectivamente deben aplicarse buscando equilibrar las demandas básicas de los escolares. Se difunde e intensifica una conflictiva social según la cual las escuelas han ido poco a poco cambiando su función (Dussel; Finocchio, 2003), transformándose en sitios de contención social, donde el comedor escolar (copa de leche, almuerzo) insume el importante tiempo de la estructura curricular contabilizado para cumplimentar la enseñanza. Las funciones del director de escuela se complejizan, su rol se ve asediado por distinto tipo de trámites a gestionar, no pudiendo desempeñarse como "gestor", como lo requiere la reforma.

Los docentes - particularmente en el nivel básico - también truecan funciones.

Podrá decirse que la función de maestramamá, director-jefe comunitario, profesor-asistente 
social, fueron inherentes a la condición del ejercicio profesional de la enseñanza desde la época del normalismo y que en las actuales circunstancias se reafirma su continuidad. Sin embargo, hay diferencias. El panorama del centro escolar ya no es rural ni suburbano, esta circunstancia se ha convertido en una continuidad, el bajo rendimiento de los alumnos generaliza en la práctica - ese estado; la homogeneidad del perfil escolar populariza el desinterés o la baja motivación por el aprendizaje; el currículum no es diferente y abierto, se des-estructura ante la emergencia de condiciones vitales...

En el complejo escenario que se dibuja, se imponen transformaciones de fondo, que permitan superar un análisis externo sobre el quehacer del sistema educacional y la función que compete a los profesionales docentes.

En la búsqueda de argumentos que justifiquen nuevos posicionamientos, se efectuará un rastreo comparativo y contrastivo sobre las interpretaciones acerca de la FD, antes y después del período que aquí se trata, hasta pronunciar las circunstancias que hoy definen su actuación.

\section{Tradiciones y estilos en la Formación Docente}

Para poder interpretar el tipo de FD que se experimenta en nuestro medio conviene efectuar una rápida ubicación de los fundamentos ideológicos que la sostienen y de las formas organizativas que asume en los períodos sociohistóricos considerados, de modo a advertir el grado de adecuación o pertinencia de los programas formativos con los cambios que se experimentan a nivel social.

Se interpreta a la FD como el "elemento estratégico en que las regulaciones sociales y las relaciones de poder se llevan a efecto" (Popkewitz, 1994, p. 104), correspondién-dose con "múltiples conexiones socioeconómicas e ideológicas que median entre las escuelas y la estructura social general" (Giroux, 1987, p. 75). Dichas conexiones armarian las estructuras superficial y profunda de significado (Popkewitz,
1988), que permiten interpretar cómo el profesor (así como el niño o el conocimiento) "son concebidos como productos históricos y como el espacio en que tienen lugar ciertas prácticas, tecnologías y procedimientos institucionales de subjetivación" (Popkewitz, 1994, p. 131). Dicho de otro modo, "las cuestiones relacionadas con el significado y el objetivo de los programas de formación del profesorado son de naturaleza política" (Giroux, 1987, p. 57). Se traducen en forma de supuestos, creencias y reglas implícitas, legitimando las acciones y prácticas adoptadas en el programa formativo. Impregnan los comportamientos, pautas de lenguaje y acciones que configuran al futuro docente, respondiendo a códigos culturales propios de las estructuras de poder. Trasuntan ideología en tanto grupo de conceptos, creencias y valores, organizados en ciertos códigos lingüísticos como los mensajes de autoridades educacionales, el plan de estudios, la selección bibliográfica, entre otros.

Regulan y producen capacidades sociales a través de los programas de formación del profesorado, los que "funcionan como factores de control social" (Giroux, 1987, p. 71).

La expresión "regulación social” refiere a elementos activos de poder que actúan para generar disciplina en la capacidad de los individuos, interpretando que hay reglas y normas en la práctica social, que pueden leerse como un texto. Hay lenguaje, rituales y comportamientos que suceden en el contexto institucional e impregnan la forma de pensar, sentir, actuar del docente; vertebrando la estructura profunda de su práctica.

La FD, vista como un proceso de regulación (Popkewitz, 1990; 1994; 1995), conlleva una carga de intencionalidad política e ideológica; así la tarea escolar, a cargo de docentes que orientan o conducen a alumnos se asume como "productos históricos y como el espacio en que tienen lugar ciertas prácticas, tecnologías y procedimientos institucionales de subjetivación" (1994, p. 131).

Asumiendo este posicionamiento, se advierten tres o cuatro encuadres ideológico - 
prácticos en la FD inicial en el medio local, varios de ellos en correspondencia con la organización adoptada a nivel nacional.

1 - La primera experiencia sistemática de FD en la provincia se efectúa en las Escuelas Normales. Estas - localizadas en Salta como en otras provincias del país - se trazaron y funcionaron siguiendo el modelo capitalino central del país (Birgin; Duschatskt; Dussel, 1998), tanto en lo orgánico como en los fines y desarrollo de planes de estudio. La importancia de este modelo de FD normalista es marcada, tanto porque su origen remonta al período de organización nacional (fines del siglo XIX) como por la perdurabilidad del enfoque y la continuidad de la reproducción de sus prácticas. El Normalismo acentúa la preparación de maestros que fomenten el aprendizaje de la norma o la regla, y la conducta de adhesión a la ley y orden emanados del Estado. Este encarna en la función docente la preparación cívica de las nuevas generaciones, las que crecerán con sentido de argentinidad y con reconocimiento de sus límites geográficos e ideológicos.

El enfoque adoptado por el Normalismo efectúa una mixtura entre la visión ideológica liberal (la defensa de la república, el nacionalismo), el autoritarismo y el cultivo de cierta mística, tanto en la figura docente como en la confianza en el desarrollo espiritual del alumno, con escaso interés por los procesos del aprender y sus fundamentos, limitando la interpretación de la enseñanza como una práctica ritualista y rutinaria, de corte preceptivo y repetitivo, independiente del contexto, de las relaciones que en él se desarrollan y de niveles explicativos que orienten la actuación profesional docente. De allí que se enseñe tipo "modelo" o "receta" y se anule - mediante esta práctica - el reconocimiento de variantes, variables, acontecimientos novedosos o diferentes o la irregularidad de situaciones de enseñanza y de aprendizaje. Esta concepción de la enseñanza como un tipo modélico, conserva- do, cerrado, pervive en las aulas de educación básica y ha trasuntado incluso al nivel medio/ Polimodal (Chaile, 2001).

2 - Entre los estilos de discurso de mayor impacto en la interpretación "favorable" de la formación y la práctica docente se debe citar el discurso de la razón instrumental o de la identificación de los medios a través de los cuales se alcanzan satisfactoriamente los objetivos trazados. Desde la posición del Tecnicismo se irradia una imagen de pensamiento racional y eficiencia institucional, evitando el reconocimiento de supuestos y relaciones sociales implícitas en las estructuras de poder en la sociedad.

Este enfoque, que se divulga en los '60, '70, se preocupa por buscar la elevación del nivel cultural del docente, propicia el desarrollo de bases científico-tecnológicas en su preparación. La FD aludida hace un esfuerzo, al menos teórico, por capacitar al docente en los procesos de planificación, conducción y evaluación de los aprendizajes, desde un modelo tecnicista. Se avanza - parcialmente hacia el desarrollo de grados de autonomía de la FD, al menos en el sentido de alejar la imagen del maestro del centralismo estatal a que estaba confiada su misión. Se procura, en cambio, preparar un agente que técnicamente pueda aprovechar, coordinar y regular herramientas de tipo profesional (el plan, los objetivos, el tiempo, los recursos, la escuela como unidad de cambio). Pero en este modelo de FD nuevamente se cae en la estandarización de pautas y modelos de acción, que tornan dependentista el trabajo profesional docente. La falla radica en "bajar" matrices o esquemas que, articulado al escaso ejercicio reflexivo del docente, y animado por la divulgación de la novedad, deviene en la copia de planificaciones, objetivos, planes de organización escolar... Sin embargo se ha producido un movimiento en las escuelas y en la FD. El docente - desde el discurso y desde las acciones de formación comienza a considerarse y a ser considerado un técnico. 
El contexto social y las transformaciones de tipo tecnológico que modernizan a la Argentina de esa época, repercuten en fomentar una nueva propuesta formativa, que intenta superar el tradicionalismo en la FD, en la enseñanza, en la concepción educativa.

Este breve período de modificaciones retrotrae ante la emergencia de cambios interpretativos que - de la mano del militarismo en el país a partir de 1976 - obran en contra de los propósitos tecnicistas, a poco de haberse implementado. La currícula de la FD se revisa, por orden de las juntas militares, se limita la bibliografía y se cancela la emisión de opinión o interpretación diferente a la que proclama el gobierno de facto. El grupo de egresados docentes salidos de los Institutos Normales y de los Profesorados universitarios en este período desconocieron, a partir de su formación, paradigmas distintos al sostenido por el régimen, para comprender los procesos sociales, políticos, económicos, sesgando su visión y futuro análisis. La FD en la provincia se sostiene en una práctica reproductivista y direccionada, pero no innovadora.

Sin embargo, el caso particular de Salta muestra las posibilidades de un quehacer innovador en especial en el nivel Superior No Universitario, aprovechado por los gestores de direcciones educativas o por rectores de institutos del período. Llámese por el nivel social mantenido en los círculos de relación, por el espíritu católico que permea dichas relaciones (que en el medio es ampliamente influyente), o por ambos factores, el gobierno provincial de facto habilitó espacios para la generación e innovación educativa en forma de carreras de FD de profesores de nivel inicial, de educación especial y aún de preparación para la enseñanza media, tanto en la capital como en el interior. Esta muestra de progresismo e innovación es doblemente notoria, por un lado porque brinda respuestas a requerimientos y demandas de las poblaciones del interior y porque abre la formación a la preparación sistemática de cuadros docentes en especialidades nuevas en el medio (excepto alguna formación brindada por la universidad local). Otro factor explicativo puede residir en el carisma circunstancial de gobernantes, directivos, gestores de la educación en el período. Una cuarta vía explica las acciones por la necesidad política de brindar una plataforma de acciones que conformen a la población y recoja adherentes.

$\mathrm{Si}$, como dice el enfoque de la regulación, la FD normatiza el espacio en que los futuros docentes van subjetivando prácticas, tecnologías y procedimientos institucionales permitidos (por omisión de otros que al no presentarse no serán incorporados sino desconocidos o rechazados), entonces esta FD innovadora pero no amplia, socialmente respondente pero no más comprometida que lo permitido, asegura un espacio político e ideológico para la conformación de los agentes sociales en formación.

Como en otros currículos de FD éste muestra limitaciones de tipo bibliográfico, se evitan las prácticas - por la trascendencia comunitaria que pudieren implicar - e insiste en el trabajo con el alumno, no así en el contexto.

3 - Cuando, en el retorno de la democracia (1983) la política educacional local impulsa los estudios de profesorados de nivel primario y medio, emplea la consabida estrategia regional de brindar respuesta a las demandas sociales a través de la extensión e intensificación de apertura de Institutos donde se ofrecen estudios de FD. En un clima social y en un contexto normativo diferente al período anterior, la docencia vuelve a ser pensada y asumida por los sectores sociales bajos como un canal de acceso al trabajo formal, por lo que los Institutos se ven poblados de gente "con vocación docente". Mirado desde las reales necesidades del medio, la meta de la cobertura educacional coincide con la expansión de la escolaridad en la región. Sin embargo, el tema de la calidad educativa, así como de la calidad de la FD aún no reúne condiciones. La argumentación esbozada en la normativa de aprobación de los planes de estudios, en lo referido a la concepción que sustentarían los estudios, el tipo de docente a 
preparar, los principios y criterios de elaboración de la currícula, la intencionalidad de la práctica formativa, es básica o escasa.

Ante la carencia de fundamentos formativos, los institutos formadores adoptan en la práctica modelos mixturados, en ocasiones "recortados", con preeminencia del normalismo, el tradicionalismo, algún grado de tecnicismo, la reproducción de formas aprendidas en la historia escolar de cada docente, así como con sesgos de improvisación y confusión.

El perfil docente derivado ha sido criticado por su baja calidad formativa. En su desempeño profesional las limitaciones de formación imposibilitarian el análisis crítico respecto al medio y las obturaciones culturales, políticas, tecnológicas que obliteran las posibilidades de desarrollo del medio local; asimismo se descalificaría por el impreciso dominio y actualización de conocimientos, a juzgar por evaluaciones derivadas de su desempeño aúlico. Si acaso la política de FD implementada en el período reseñado quiso reproducir el ideal misional del docente, obró limitando su formación desde una mínima base organizativa y de fundamento, con escaso desarrollo para el manejo de competencias autónomas y con dificultades para definir una propuesta políticopedagógica de acción. Aunque ello no invalida lo importante que haya resultado ofrecer una salida laboral, en especial para la población femenina, y que se haya expandido la FD que la provincia requiere.

Además ha de reconocerse cierto desarrollo de un plan cíclico de oferta de maestros para la escuela primaria, la que - estudiada en su saturación - se reemplaza con estudios del profesorado para el nivel secundario, tanto en la capital como en el interior.

4 - Recién en el período de la Transformación Educativa los Institutos Superiores adhieren a una nueva forma organizativa y efectúan la revisión curricular de sus planes y oferta formativa, conforme a lineamientos del proceso de evaluación de carreras y de validación de la calidad del profesorado. Se trata de un proceso impuesto desde los planos de decisión externos, antes que derivado de la solicitud de los profesores, de las instituciones formativas o del pedido comunitario ${ }^{4}$.

La nueva propuesta curricular que sustenta la FD se caracteriza por actualizar enfoques, adecuar la preparación a los requerimientos escolares e incluso sociales, pero observa limitaciones en cuanto al modelo organizativo que se adopta en la Provincia (soslayando orientaciones explicitadas por la Transformación). Olvidando que la gestión de la educación significa en primer lugar el acercamiento de un sinnúmero de insumos a los establecimientos educativos y en segundo lugar la movilización y el acompañamiento a protagonistas para que en pleno ejercicio de su creatividad construyan mejores procesos de aprendizaje a través de buenas prácticas de enseñanza (Braslavsky, 1999), se limitan cargos, funciones, y se reubica el modelo verticalista y tradicional de gobierno escolar en las instituciones. Se demuestra que "el compromiso por llevar adelante la [...] reforma [...] es débil" (Corrales, 1999, p. 7). Su carácter impositivo es otra limitante, derivada de decisiones del gobierno por asumir la adecuación del sistema educacional de acuerdo a pautas indicadas por los organismos que fomentan el préstamo para la ejecución de la reforma. No se trata de un movimiento originariamente fundamentado en la reflexión y decisión del cuerpo de profesores. Este acatamiento de la reforma desde lo externo o superficial ocasiona baja adhesión a los fines educacionales perseguidos, continuidad del trabajo escolar burocrático y escaso nivel de confianza en su proyección. Incide además la conflictiva del bajo salario, el malestar docente por la sobreabundancia de problemas sociales en las aulas, el contraste entre la responsabilidad del trabajo escolar y la mínima

4. Se exceptúa el período de implementación del Programa de Transformación de la Formación Docente (PTFD) (1992-96), en que los Institutos de las Escuelas Normales participaron de la propuesta ofrecida por el Ministerio de Educación de la Nación. Este movimiento se suspendió cuando se procedió a aplicar la Transformación Educativa de modo generalizado en el país. 
propiedad de desempeños en los alumnos, problemas todos estos que van tornándose clásicos en el escenario local, en los inicios de la nueva centuria.

El enfoque de trabajo formativo docente adoptado por la reforma es neo-tecnicista, caracterizándose por esquematizar el modelo curricular, marcar su distribución por módulos, horas y etapas evaluativas. Busca promocionar la FD que la empresa actual necesita (ya no el Estado), incorpora las tecnologías (particularmente las TICs) en el estudio curricular (aunque los Institutos tienen escasa dotación de PCs y redes de conexión) e incluye el estudio del contexto desde la transversalidad (que sin embargo, en el trabajo curricular se diluye). Se propone modificar la Formación Docente para la escuela del siglo XXl y adecuarla al nuevo contexto de transformaciones. Problemas derivados del manejo del contexto, la conflictividad de la región, la pobreza extendida, sin embargo, no pueden echar un manto de ocultamiento al desarrollarse los procesos formativos, por lo que éstos se ven alterados al renovar constantemente la planta profesional, al manejar bajos fondos para la función investigativa, al ver limitados los recursos tecnológicos institucionales. Se trastocan los fines de la formación y de la capacitación y desarrollo profesional docente, en un panorama confuso e inestable.

\section{Cambios y limitaciones de la Formación Docente, requerimientos y tensiones}

Ante la situación actual de cambios y transformaciones en la sociedad de los tiempos recientes y dado el tipo de FD propiciado por los enfoques y modelos formativos respectivos, resta mencionar los grados de adecuación o diferencia entre los proyectos de FD logrados o en curso, en relación con la posición, las condiciones, los requerimientos, los intereses que el contexto - particularizado al medio - solicita de la preparación profesional docente. Se observa:

- La actual política educacional de FD ha modificado normas y ha superado su planificación y concurrencia desde los organismos del Estado, para reemplazarla por el cumplimiento de una normativa que deja "libre" a las instituciones para que estudien sus propuestas (Sennett, 2000; Pineau, 2003 en Dussel; Finocchio, 2003). Estas se evalúan y supervisan pero el compromiso de desarrollo cae sobre el cuerpo profesoral y directivo que lo ha propuesto. En realidad, la libertad de que gozan los Institutos para proyectar y elevar corresponde a la política de retracción del Estado y su reemplazo por la acción comprometida de organismos que "ofrecen" en el mercado su propuesta formativa. Para el caso de la FD las posibilidades de oferta y de elección se limitan al círculo de concurrencia en el medio en que se localiza la institución.

- La FD - en las últimas décadas - ha obrado de paracaídas para que jóvenes de una clase media en decadencia busquen obtener un título que les garantice su inserción laboral formal. También lo es para los jóvenes procedentes de clases bajas, con el agravante de que sus limitaciones de capital cultural y social inciden en la baja calidad del egreso, deteriorándose - ya desde la formación - el perfil del futuro docente (Tenti Fanfani, 2003; Tedesco; Tenti Fanfani, 2002). En el medio, no obstante, el maestro o profesor continúan siendo figuras incidentes, requeridas, necesarias, para orientar y acompañar la niñez y adolescencia de la población escolar. Se señala aquí un problema que tensiona la relación entre la FD y la necesidad local, toda vez que la política formativa sostiene una promesa de igualación a través de las prácticas de preparación de maestros, cuando su inserción laboral se efectuará luego en los sitios de mayores carencias y donde - paradójicamente - se requiere lo mejor en calidad formativa.

- En la actualidad la FD inicial se organiza curricularmente en base a la estandarización de 
normas y de acuerdo a criterios neo-tecnicistas. Se trata de proyectos institucionales que se trabajan y fundamentan, debiendo incluir la Práctica y el sentido de su presencia desde los inicios de la preparación docente. Si se efectúa una mirada interna al desarrollo curricular se ve que subsisten limitaciones tanto de cumplimiento de cada propuesta como de desarrollo del nivel crítico reflexivo con que se requiere preparar a los noveles profesores. La reforma no llega a modificar los perfiles internos del cuerpo profesoral, en particular de los titularizados, obrando ello como obstáculo en el compromiso de adhesión e interpretación de los cambios.

- Los proyectos curriculares de FD oscilan - en sus fundamentos - desde el Normalismo, la base espiritualista y las posiciones tecnocráticas, que se retoman en la década del '90 bajo el modelo neoconductista. Estos enfoques subsisten mixturados y el último de los mencionados no llega a desplazar la impronta normalista que particularmente la sociedad local aún persigue del docente. Otra cosa son las modificaciones efectuadas al divulgar la importancia del dominio técnico-metodológico en los docentes. Son expresiones declarativas y no logradas totalmente, pues los cuadros disciplinaristas continúan otorgando importancia al dominio específico de las ciencias, en una renovada manifestación de sus bases de formación positivista. La "verdad cientifica" se impone desde el caudal informativo, el dato, la certeza, antes que "la construcción de los procesos del aprender ese contenido científico", lo que desbalancea la importancia que la FD pretende lograr en el docente que prepara.

- Frente a ello, la actualidad de planteos y posturas interpretativas ante la función de la escuela, señala - más que la importancia de dominar los contenidos - el saber enseñarlos, en el sentido que la obtención de la información se ve facilitada pero subsiste la necesidad de orientar al niño o joven en los procesos de alfabetización inicial, selección y recorte del dato, su procesamiento y organización, más llegar a elaborar posiciones reflexivas ante el cúmulo de información y lectura que se tiene a la vista. Todo ello reivindica la necesidad de fortalecer e dominio de los procesos de intervención didáctica por los docentes. Incluye una revisión constante de las teorias del aprendizaje, en particular ante el avance de las TICs y la cercanía del acceso al dato, lo que se torna en una imposibilidad para aquellos que carecen de medios de simbolización, codificación y abstracción. Allí la tarea del docente continúa siendo insustituible.

- Las escuelas del medio se ven cada vez más privadas de muros que la separen de la conflictiva social externa. Se inundan de problemáticas cuya solución desplaza la atención del trabajo curricular hacia la solución de casos urgentes. Esta situación tensiona la relación entre los requerimientos de calidad formativa que pronuncia e impone una sociedad desarrollada, y las condiciones de difícil cumplimiento o alcance que los docentes exponen. Como se expresa más adelante, la función docente ha cambiado y ha mutado desde la difusión de conocimientos a la orientación de calidad. Pero el trastoque en nuestro medio es diferente y se pronuncia desde la enseñanza a la asistencialidad, incidiendo en la baja competitividad que la escuela de la región expone frente a las exigencias de la globalización y de un mercado de trabajo cada vez más excluyente. El efecto es la disminución de las condiciones de autonomía del trabajo docente, tanto en el manejo de criterios propios como en las condiciones en que debe realizar su trabajo.

\section{Algunas ideas para re-pensar las tensiones y limitaciones de la Formación Docente}

Es necesario repensar, revisar, reanalizar la política de FD, habida cuenta que en la sociedad local la profesión docente - como acto de preparación o como actualización de competencias profesionales - convoca a un importante sector. Este grupo, a su vez, dado sus condiciones de limitación simbólica y cultural, exige propuestas pedagógicas diferenciadas de preparación, que al tiempo que compensen las deficiencias, acentúen 
la particularidad del servicio profesional al medio. Superar la homogeneidad sería un importante clave de trabajo curricular en la FD.

Conviene una política educacional de FD destinada a promover el servicio de atención a nuevos grupos poblaciones con quienes compartir la responsabilidad y el compromiso por el aprender y el saber. El dominio del conocimiento, asumido no sólo como medio de asegurar la competencia en el mercado - como expresa la sociedad neo-liberal - sino como el espacio para la construcción particular o colectiva de saberes que ayuden a solucionar problemas, necesidades, requerimientos o demandas de otros grupos poblacionales solicitantes y coetáneos, sería un volver a la idea ilustrada del gusto por el saber.

Conviene por ello una política que se preocupe por considerar - del amplio mapa de necesidades - aquéllas que pugnen por la superación de propuestas no más acordes con los requerimientos de la sociedad en transformación que se vive, esto es, superar la homogeneidad como criterio de formación y reformular hacia la diferencia y la particularidad; promocionar la colaboración y no el trabajo individual de clases, avanzando hacia la práctica de Taller, la jornada de trabajo con propósitos claros, la interárea de trabajo, revisar las posiciones fundamentalistas en torno a la defensa del nacionalismo y el patriotismo, para pensar alrededor de la comunidad o la patria compartida, que reposicionan intereses en el mundo global. Asimismo se requiere formar docentes pensantes que reformulen los principios de igualdad y equidad ya no sólo como acceso, apertura del espacio escolar, sino como equilibrio de competencias alcanzadas, permanencia, retención y logro de titulaciones en los distintos niveles del sistema. Es imprescindible asumir la práctica de la inclusión social trabajada permanentemente para con las comunidades de mayor vulnerabilidad social.

Se trata de volver a plantear el debate pedagógico en un tono público y político, que supere la estructura organizativa neotecnicista de la Reforma, para volver a corporeizar intereses y necesidades de la comunidad local. Seguramente no se perseguirá el trazado de una FD para la sociedad global, pero no es conveniente dejar de considerarla. Antes bien, corresponde armar un proyecto social relevante en que los docentes se conviertan en sujetos pensantes y reflexivos, que apuesten al dominio del conocimiento necesario y del desarrollo tecnológico aprovechable en la zona, que se preocupen por la gestión de estrategias modernas y versátiles, que practiquen una enseñanza para la curiosidad, el problema a resolver y el caso cuestionable, sobre la base del desarrollo ético y político de la ciudadanía responsable.

Ello requiere de una voluntad política de proyección del desarrollo, de la elaboración de una planificación factible aunque ambiciosa, y de una toma de decisiones que considere el futuro como meta alcanzable, sobre la base de la superación efectiva de las actuales condiciones sociales limitativas de la región. 


\section{Referências bibliográficas}

BECERRA, M. Sociedad de la información: proyecto, convergencia y divergencia. Buenos Aires: Ed. Norma. 2003.

BIRGIN, A., DUSCHATZKT, S., DUSSEL, I. Las instituciones de formación docente frente a la reforma: estrategias y configuraciones de la identidad. Revista Propuesta Educativa, Buenos Aires, año 9, n. 19, p. 24- 35, Diciembre. 1998.

BRASLAVSKY, C. La reforma educativa en Argentina: avances y desafíos. Revista Propuesta Educativa, Buenos Aires, año 10, n. 21, p. 80- 88, Diciembre.1999.

Las políticas educativas frente a la revolución tecnológica en un mundo de interdependencias crecientes y parciales. IIPE - UNESCO, Buenos Aires. 2000.

BRUNET, I.; VALERO, L. El papel de la educación en la era de la información. Universidad Nacional de Salta / Universidad Rovira i Virgili: Materiales de Trabajo para el Curso "Las políticas educativas de finales del Siglo XX". 2000.

Educación y economía. Barcelona: Universitat Internacional de Catalunya. 1998.

Del Estado de los derechos sociales al Estado Asistencial: sociedad y educación en las sociedades avanzadas. Barcelona: Librería Universitaria. 1997.

BRUNNER, J. J. Educación: escenarios de futuro. Nuevas tecnologías y dociedad de la información, Santiago de Chile: PREAL, ก. 16, 2000.

CARNEGIE FORUM ON EDUCATION AND THE ECONOMY. Task Force on teaching as a profession: A nation prepared: teachers for the $21^{\text {st }}$ century the report of the Task Force on teaching as a profession. Washington. 1986.

CASTELLS, M. La ciudad informacional. Madrid: Alianza, 1995.

CORRALES, J. Aspectos políticos en la implementación de las reformas educativas. Nuevas tecnologías y dociedad de la información, Santiago de Chile: PREAL, n.14, 1999.

CHAlLE, M. 0. Modelos de formación docente en Salta: comparación de políticas, tiempos e instituciones. Identificación de aciertos y problemas comunes. ENCUENTRO: ESTADO DE LA INVESTIGACIÓN EDUCATIVA: "ENSEÑANZA MEDIA. REALIDAD Y DESAFIO". XI. Córdoba: Universidad Católica de Córdoba - Centro REDUC. 2001. Disponible en http://www.uccor/reduc.

CHOMSKY, N. Crisis, democracia y mercados en el nuevo orden mundial. Wayruro: REBELION,1999.

CHOMSKY, N.; DIETERICH, H. La sociedad global: educación, mercado y democracia. Universidad de Buenos Aires: Oficina de Publicaciones. 1996.

DUSSEL I, Y.; FINOCCHIO, S. Enseñar hoy: una introducción a la educación en tiempos de crisis. Buenos Aires: Fondo de Cultura Económica de Argentina S. A., 2003.

GARCÍA CANCLINI, N. La globalización imaginada. $2^{\circ}$ reimpresión. Buenos Aires: Ed. Paidós., 2000.

GIROUX, H. La formación del profesorado y la ideología del control social. Revista de Educación. Madrid, n. 284, p. 53-74. 1987.

HOLMES GROUP. Tomorrow's teachers: a Report of the Holmest Group, Michigan. 1986.

KLISKEBERG, B. El rediseño del Estado. Buenos Aires: Fondo de Cultura Económica. s/f.

LARROSA, J. (Editor). Escuela, poder y subjetivación. Genealogía del Poder. Madrid: La Piqueta. 1995.

PEDRÓ, F.; ROLÓ, J. M. Los sistemas educativos iberoamericanos en el contexto de la globalización: interrogantes y oportunidades. Revista Iberoamericana de Educación, n.12, p. 1996.

PINEAU P. 0 escuela o crisis: crónicas marcianas del imaginario docente actual. En: DUSSEL I, Y.; FINOCCHIO, S. Enseñar hoy: una introducción a la educación en tiempos de crisis. Buenos Aires: Fondo de Cultura Económica de Argentina S. A., p. 118. 2003. 
POPKEWITZ, T. Paradigma e ideología en investigación educativa: las funciones sociales del intelectual. Madrid: Editorial Mondadori. 1986.

Ideología y formación social en la formación del profesorado: profesionalización e intereses sociales. Madrid: MEC, Revista de Educación, n. 285, p. 125-148. 1988.

Formación del profesorado: tradición, teoría y práctica. España: Servei de Publications, Universitat de Valencia. 1990. . Política, conocimiento y poder: algunas cuestiones para el estudio de las reformas educativas. Madrid: MEC, Revista de Educación, n. 305, p. 103-137. 1994.

La relación entre poder y conocimiento en la enseñanza y en la formación docente. Revista Propuesta Educativa. Buenos Aires, año 6, n. 13, p. 30-43. 1995.

SENNETT, R. La corrosión del carácter. Las consecuencias personales del trabajo en el nuevo capitalismo. En: DUSSEL, I.; FINOCCHIO, S. Enseñar hoy: una introducción a la educación en tiempos de crisis. Buenos Aires: Fondo de Cultura Económica de Argentina S. A., p. 61, 2003.

SUÁREZ, D. Formación docente y prácticas escolares: notas para una tensa relación. Revista IICE, Facultad de Filosofía y Letras UBA, Buenos Aires, año II, n. 2, p. 38-51, Julio. 1993.

TARDIF, M. et al. La formación de maestros en Europa y América del Norte según los nuevos enfoques profesionales de la enseñanza. Revista Propuesta Educativa, Buenos Aires, año 10, n. 22, p. 49-60, Junio. 2000.

TENTI FANFANI, E. Algunas dimensiones de la profesionalización de los docentes: representaciones y temas de la agenda política. IIPE Buenos Aires (Sede Regional del Instituto Internacional de Planeamiento de la Educación). p. 9-10; 14-15-16. 2003

TENTI FANFANI, E.; TEDESCO, J. C. Nuevos tiempos y nuevos docentes. Conferencia Regional "O desempheno dos profesores na América Latina e Caribe: Novas prioridades". BID/UNESCO/MINISTERI0 DA EDUCACAO, Brasilia. p. 9-11. 2002.

TRAHTEMBERG, L. El impacto previsible de las nuevas tecnologías en la enseñanza y la organización escolar. Revista lberoamericana de Educación, OEI, n. 24, p. 2002.

Recibido en 31.03 .06

Aprobado en 05.03.07

Marta Ofelia Chaile es la autora se desempeña en cátedras pedagógicas de Formación del Profesorado de la Facultad de Ciencias Exactas de la Universidad Nacional de Salta. Revista como Directora e Investigadora de Proyectos de Investigaciones del Consejo de Investigaciones de la Universidad Nacional de Salta. Es Doctora en Educación. 